\title{
Ruminal methane inhibition potential of various pure compounds in comparison with garlic oil as determined with a rumen simulation technique (Rusitec)
}

\author{
Carla R. Soliva ${ }^{1 *}$, Sergej L. Amelchanka ${ }^{1}$, Stéphane M. Duval ${ }^{2}$ and Michael Kreuzer ${ }^{1}$ \\ ${ }^{1}$ ETH Zurich, Institute of Agricultural Sciences, CH-8092 Zurich, Switzerland \\ ${ }^{2}$ DSM Nutritional Products, NRD/CA, BP 170, F-68305 Saint-Louis Cedex, France \\ (Received 29 June 2010 - Revised 23 November 2010 - Accepted 6 December 2010 - First published online 18 April 2011)
}

\begin{abstract}
Ruminants represent an important source of methane $\left(\mathrm{CH}_{4}\right)$ emissions; therefore, $\mathrm{CH}_{4}$ mitigation by diet supplementation is a major goal in the current ruminant research. The objective of the present study was to use a rumen simulation technique to evaluate the $\mathrm{CH}_{4}$-mitigating potential of pure compounds in comparison with that achieved with garlic oil, a known anti-methanogenic supplement. A basal diet $(15 \mathrm{~g} \mathrm{DM} / \mathrm{d})$ consisting of ryegrass hay, barley and soyabean meal $(1: 0 \cdot 7: 0 \cdot 3)$ was incubated with the following additives: none (negative control); garlic oil (300 mg/l incubation liquid; positive control); allyl isothiocyanate ( $75 \mathrm{mg} / \mathrm{l})$; lovastatin (150 mg/l); chenodeoxycholic acid (150 mg/l); 3-azido-propionic acid ethyl ester (APEE, $150 \mathrm{mg} / \mathrm{l}$ ); levulinic acid (300 mg/l); 4-[(pyridin-2-ylmethyl)-amino]-benzoic acid (PABA, $300 \mathrm{mg} / \mathrm{l}$ ). Fermentation profiles (SCFA, microbial counts and $\mathrm{N}$ turnover) and $\mathrm{H}_{2}$ and $\mathrm{CH}_{4}$ formation were determined. Garlic oil, allyl isothiocyanate, lovastatin and the synthetic compound APEE decreased the absolute daily $\mathrm{CH}_{4}$ formation by $91,59,42$ and 98\%, respectively. The corresponding declines in $\mathrm{CH}_{4}$ emitted per mmol of SCFA were 87, 32, 40 and 99\%, respectively, compared with the negative control; the total SCFA concentration was unaffected. Garlic oil decreased protozoal numbers and increased bacterial counts, while chenodeoxycholic acid completely defaunated the incubation liquid. In vitro, neutral-detergent fibre disappearance was lower following chenodeoxycholic acid and PABA treatments ( -26 and $-18 \%$, respectively). In conclusion, garlic oil and APEE were extremely efficient at mitigating $\mathrm{CH}_{4}$ without noticeably impairing microbial nutrient fermentation. Other promising substances were allyl isothiocyanate and lovastatin.
\end{abstract}

Key words: Methanogenesis: Rumen: In vitro techniques: Garlic oil

Ruminant digestive processes represent a significant source of the greenhouse gas methane $\left(\mathrm{CH}_{4}\right)$. For this reason, public and political pressure is intensifying for decreasing $\mathrm{CH}_{4}$ emissions from livestock, and numerous efforts are underway to achieve this goal ${ }^{(1)}$. Among these are a number of nutritive strategies designed to mitigate enteric $\mathrm{CH}_{4}$ formation by focusing on the potential addition of distinct plants or extracts rich in secondary compounds to animal feeds ${ }^{(2,3)}$. One promising form of these secondary compounds is garlic oil, which consists of a mixture of various plant secondary metabolites such as allicin, diallyl sulphide, diallyl disulphide and allyl mercaptan ${ }^{(4)}$, and which has shown appreciable in vitro capacity for mitigating ruminal $\mathrm{CH}_{4}$ formation $^{(5,6)}$. However, the exact nature of the active ingredient in the complex garlic oil mixture is not yet known.

Ruminal $\mathrm{CH}_{4}$ mitigation experiments that have tested pure substances are scarce, although several natural as well as synthetic compounds currently seem promising. One important group of natural compounds is represented by the glucosinolates, which are thioglucosides that undergo hydrolysis when the vegetative parts of the plants are damaged, resulting in a range of potentially toxic isothiocyanate compounds $^{(7)}$; for example, allyl isothiocyanate that originates from the seeds of black mustard (Brassica nigra) ${ }^{(7)}$. Other compounds, such as lovastatin, which naturally occurs in oyster mushrooms, are inhibitors of hydroxy-methylglutarylcoenzyme A reductase and can inhibit the growth of selected methanogenic microbes, thereby preventing $\mathrm{CH}_{4}$ formation ${ }^{(8)}$. Mammalian bile acids ${ }^{(9)}$, such as chenodeoxycholic acid ${ }^{(10)}$, are also known to inhibit the activities of intestinal bacteria. The modes of action of secondary compounds with respect to their anti-methanogenic effects have not yet been identified in detail. Although direct effects against methanogens are probable, indirect effects are also possible through the

Abbreviations: APEE, 3-azido-propionic acid ethyl ester; CP, crude protein; NDF, neutral-detergent fibre; OM, organic matter; PABA, 4-[(pyridin-2-ylmethyl)aminol-benzoic acid.

*Corresponding author: C. R. Soliva, fax +414463211 28, email solivac6@gmail.com 
suppression of ruminal protozoa or ruminal fibre degradation or both, resulting in a lower supply of $\mathrm{H}_{2}$ to the methanogens ${ }^{(11)}$. In the specific case of garlic oil, the $\mathrm{CH}_{4}$-mitigating effect may be directly attributed to the toxicity of organosulphur compounds, such as diallyl sulphide and allicin, to the methanogens ${ }^{(11)}$.

Besides natural substances, a number of synthetic compounds are also known to abate ruminal $\mathrm{CH}_{4}$ formation. Kitano et $a l .{ }^{(12)}$ and Ghorpade \& Hanna ${ }^{(13)}$ reviewed the properties of the synthetic compound levulinic acid, and suggested that it has the potential as an animal feed additive, a fuel extender and a food antimicrobial agent. Levulinic acid can be readily and inexpensively prepared from sugar cane, sugarbeet molasses, wood wastes, starch and cellulose ${ }^{(14)}$. Its influence on nutrient digestibility and ruminal fluid SCFA was investigated in cattle several decades ago, and it has been reported to decrease in vitro microbial activity ${ }^{(14)}$. Numerous patents have been filed in the USA concerning manufacturing, purification and further development of levulinic $\operatorname{acid}^{(15,16)}$.

The objective of the present study was to use an artificial rumen experiment to compare in vitro $\mathrm{CH}_{4}$ production from a non-supplemented basal animal diet, and a diet supplemented with garlic oil (positive control), three natural (allyl isothiocyanate, lovastatin and chenodeoxycholic acid) and three synthetic compounds (levulinic acid, 3-azido-propionic acid ethyl ester (APEE) and 4-[(pyridin-2-ylmethyl)amino]-benzoic acid (PABA)). APEE was synthesised as a structural analogue to bromoethanesulfonate, a known $\mathrm{CH}_{4}$-suppressing agent ${ }^{(17)}$. The second synthetic substance, PABA, has been shown to inhibit $\mathrm{CH}_{4}$ production of a thermophilic methanogen but to have little general effect on the growth of ruminal cultures ${ }^{(18)}$.

\section{Materials and methods}

\section{Experimental basal diet and treatment diets}

The rumen simulation technique (Rusitec), described in detail by Soliva \& Hess ${ }^{(19)}$, was used for the incubation of eight treatments in four consecutive experimental runs, each lasting for $10 \mathrm{~d}$. The Rusitec consisted of eight 1 litre fermenters. DM ( $15 \mathrm{~g}$ ) of a basal diet consisting of ryegrass hay, barley and soyabean meal (1:0·7:0.3) and a vitamin-mineral mixture $(5 \mathrm{mg} / \mathrm{g}$ diet DM containing, per g, Ca, $140 \mathrm{mg}$;, $70 \mathrm{mg}$; $\mathrm{Na}$, $80 \mathrm{mg}$; Mg, $30 \mathrm{mg}$; Se, $0.015 \mathrm{mg}$; vitamin A, $150 \mu \mathrm{g}$; vitamin $\mathrm{D}_{3}, 3 \mu \mathrm{g}$; vitamin $\mathrm{E}, 2.5 \mathrm{~g}$ ) was added to each fermenter each day. The analysed nutrient composition of the basal diet was as follows: organic matter (OM), $826 \mathrm{mg} / \mathrm{g}$ DM; crude protein (CP), $182 \mathrm{mg} / \mathrm{g}$ DM; neutral-detergent fibre (NDF), $343 \mathrm{mg} / \mathrm{g}$ DM; non-NDF carbohydrates, $333 \mathrm{mg} / \mathrm{g}$ DM.

This basal diet, without any supplementation, was used as a negative control (henceforth referred to as the 'control'). As a positive control, the basal diet was supplemented with garlic oil $(300 \mathrm{mg} / \mathrm{l}$ of incubation liquid and day). This extracted oil, produced by heating crushed garlic (Allium sativum) cloves and collecting the distilled vapour, was obtained from Aetherische Oele AG (Winterthur, Switzerland). The pure compounds tested (Fig. 1) were allyl isothiocyanate (liquid,
$>98 \%$ purity; Sigma-Aldrich GmbH, Buchs, Switzerland), lovastatin (powder, $>98 \%$ purity; TCI Europe, Zwijndrecht, Belgium), chenodeoxycholic acid (powder, $\geq 95 \%$ purity; Sigma-Aldrich Chemie GmbH, Steinheim, Germany), APEE (liquid; DSM Nutritional Products AG, Kaiseraugst, Switzerland), levulinic acid (liquid, 98\% purity; Sigma-Aldrich Chemie $\mathrm{GmbH}$ ) and PABA (powder; DSM Nutritional Products AG). Before application, powdered chenodeoxycholic acid was dissolved in $98 \%$ ethanol $(2 \cdot 33 \mu \mathrm{l} / \mathrm{mg})$, while lovastatin and

(a)<smiles>C=CCN=C=S</smiles>

(b)<smiles>CCC(C)C(=O)OC1CC(C)C=C2C=CC(C)C(CCC3CC(O)CC(=O)O3)C21</smiles><smiles>CC1CCC2C3C(O)CC4CC(O)CCC4(C)C3CCC12C</smiles>

(d)<smiles>CCOC(=O)CCN</smiles>

(e)<smiles>CC(=O)CCC(=O)O</smiles>

(f)

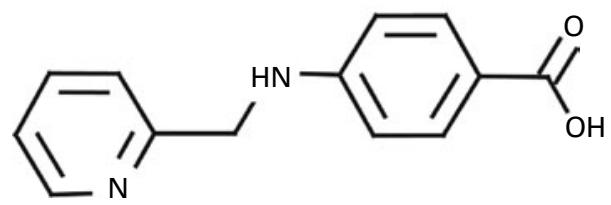

Fig. 1. Chemical structures of the compounds investigated. (a) Allyl isothiocyanate, (b) lovastatin, (c) chenodeoxycholic acid, (d) 3-azido-propionic acid ethyl ester, (e) levulinic acid and (f) 4-[(pyridin-2-ylmethyl)-amino]-benzoic acid. 
PABA powders were dissolved in $98 \%$ ethanol $(6 \mu \mathrm{l} / \mathrm{mg})$. Thus, it is possible that part of the effects observed with chenodeoxycholic acid, lovastatin and PABA could be due to ethanol, although ethanol made up $<0 \cdot 2 \%(\mathrm{v} / \mathrm{v})$ of the incubation liquid volume. Supplements were added directly to the incubation liquid, using micropipettes, every day during the process of changing the feed bags. The following concentrations of the pure substances were used $(\mathrm{mg} / \mathrm{l}$ incubation liquid and day): allyl isothiocyanate, 75; lovastatin, 150; chenodeoxycholic acid, 150; APEE, 150; levulinic acid, 300; PABA, 300.

\section{Experimental set-up}

The 1 litre fermenters were supplemented daily with experimental feed placed into nylon bags $(70 \mathrm{~mm} \times 140 \mathrm{~mm})$ with a pore size of $100 \mu \mathrm{m}^{(20)}$. To simulate the result of the chewing activity of cattle, hay was ground to pass a $5 \mathrm{~mm}$ sieve, whereas barley and soyabean meal were ground to a particle size of $3 \mathrm{~mm}$. Ruminal fluid was obtained from a lactating rumen-fistulated Brown Swiss cow that was fed hay ad libitum and concentrate (about $1 \mathrm{~kg} / \mathrm{d}$ administered in two portions) and treated according to the Swiss guidelines for animal welfare. Before use as an inoculum for the fermenters, the ruminal fluid was strained through four layers of medicinal gauze with a pore size of about $1 \mathrm{~mm}$. At the beginning of each experimental run, the fermenters were filled with $100 \mathrm{ml}$ of pre-warmed buffer ${ }^{(19)}$ and $900 \mathrm{ml}$ of strained ruminal fluid, and then maintained at $39 \cdot 5^{\circ} \mathrm{C}$. Subsequently, one nylon bag containing the respective experimental diet and one bag containing about $40 \mathrm{~g}$ fresh matter of solid ruminal contents were administered to the fermenter. The latter bag was replaced on the second experimental day with another bag containing the experimental diet. Each feed bag was incubated for $48 \mathrm{~h}$. The system was flushed with $\mathrm{N}_{2}$ gas for 3 min to maintain anaerobic conditions after the daily exchange of the feed bags. Buffer flow to the fermenters was continuous and averaged 469 (SEM 24) $\mathrm{ml} / \mathrm{d}$, resulting in a dilution rate of the incubation liquid of about $47 \% / \mathrm{d}$. The resulting incubation liquid outflow was collected in flasks and frozen at $-20^{\circ} \mathrm{C}$.

\section{Sample collection and analysis}

The $10 \mathrm{~d}$ experimental incubation period was subdivided into a $5 \mathrm{~d}$ period to allow steady-state conditions to be established within the fermenters ${ }^{(21)}$ and a $5 \mathrm{~d}$ sampling and data collection period. Every day, $3 \mathrm{~h}$ before exchanging the feed bags, incubation liquid samples were collected directly from the fermenters. Incubation liquid was then analysed for redox potential and $\mathrm{pH}$ using appropriate electrodes connected to a $\mathrm{pH}$ meter (model 634; Methrom AG, Herisau, Switzerland). Part of the collected incubation liquid samples was then centrifuged for $5 \mathrm{~min}$ at $4000 \mathrm{~g}$ (Varifuge ${ }^{\circledR} \mathrm{K}$; Heraeus, Osterode, Germany), and the supernatant was stored at $-20^{\circ} \mathrm{C}$ before being analysed for the concentration of SCFA using HPLC (System Hitachi Lachrom; Merck, Tokyo, Japan) following the procedure of Ehrlich et al. ${ }^{(22)}$. Protozoal and bacterial counts were counted daily with Bürker counting chambers $\left(0.1\right.$ and $0.02 \mathrm{~mm}$ depth, respectively; Blau Brand ${ }^{\circledR}$, Wertheim, Germany). After $48 \mathrm{~h}$ incubation, the bags with the feed residues were washed with cold water in a washing machine and stored at $-20^{\circ} \mathrm{C}$. Subsequently, the samples were lyophilised, ground to pass a sieve of $0.5 \mathrm{~mm}$ and analysed for their nutrient contents. Nutrient analysis included determinations of DM and OM (via total ash; done automatically by a TGA-500; Leco Corporation, St Joseph, MI, USA), N (C/N analyser, LecoAnalysator Type FP-2000; Leco Instruments GmBH, Kircheim, Germany; $\mathrm{CP}=6.25 \times \mathrm{N}$ ) and NDF. The latter analysis was carried out using the Fibertec System M (Tecator, 1020 Hot Extraction, Höganäs, Sweden) and adding $\alpha$-amylase to the detergent solution, but not sodium sulphite, as suggested by van Soest et al. ${ }^{(23)}$, and was expressed exclusive of ash. Dietary non-NDF carbohydrates were calculated as OS - CP NDF - total fat - ash, where total fat was analysed as a diethyl ether extract (Soxhlet method; Universal Extraction System B-811, Büchi, Flawil, Switzerland).

The fermentation gases were collected for complete $24 \mathrm{~h}$ periods in gas-tight aluminium bags (TECOBAG $8 \mathrm{~L}$, PETP/ $\mathrm{AL} / \mathrm{PE}$ - 12/12/75 quality; Tesserau Container GmbH, Bürstadt, Germany). Gas analysis included $\mathrm{CH}_{4}$ and $\mathrm{H}_{2}$ and was performed on a GC (model 5890 Series II; Hewlett Packard, Avondale, PA, USA) equipped with a flame ionisation detector (to determine $\mathrm{CH}_{4}$ ), a thermal conductivity detector (to determine $\mathrm{H}_{2}$ ) and a $234 \mathrm{~mm} \times 23 \mathrm{~mm}$ column $(80 / 100$ mesh, Porapak Q; Fluka Chemie AG, Buchs, Switzerland). The total amount of fermentation gas produced was quantified by the water displacement technique, as described by Soliva \& Hess ${ }^{(19)}$.

\section{Calculations and statistical evaluation}

$\mathrm{N}$ turnover in the individual fermenters was calculated from $\mathrm{N}$ supply, $\mathrm{N}$ disappearance from the feed bags and daily amounts of $\mathrm{NH}_{3}$ produced. Supply of dietary $\mathrm{N}$ to the fermenters came primarily from the basal diet, while only minute amounts were supplied via the addition of garlic oil, allyl isothiocyanate, APEE or PABA (chenodeoxycholic acid, lovastatin and levulinic acid are free of $\mathrm{N}$ ). Therefore, $\mathrm{N}$ turnover in the fermenters was calculated based only on the $\mathrm{N}$ content of the basal diet. $\mathrm{N}$ fractions were distinguished as follows: $\mathrm{N}$ recovered as $\mathrm{NH}_{3} ; \mathrm{N}$ present in feed residues apparently not degraded (assuming that the washing process after incubation removed most of the microbial $\mathrm{N}$ ); dietary $\mathrm{N}$ compounds apparently degraded (i.e. no longer found in the feed residues), but also not recovered as $\mathrm{NH}_{3}-\mathrm{N}$. Although there are certain remaining uncertainties, the latter fraction was assumed to provide a sufficiently accurate estimate of $\mathrm{N}$ incorporated into microbial protein. This fraction was used to estimate the microbial efficiency by relating this value to OM apparently degraded.

For statistical analysis, the mean values of the last $5 \mathrm{~d}$ per run were subjected to ANOVA using the general linear model procedure of SAS (SAS Institute, Cary, NC, USA) ${ }^{(24)}$, with supplements as fixed effects and experimental run as the random effect. Multiple comparisons among means were 
performed with Tukey's method, and differences were considered significant at $P<0 \cdot 05$.

\section{Results}

Ruminal fermentation traits were altered in various ways by supplementation with the test substances (Table 1). The redox potential of the incubation liquid, an indicator of its residual oxygen content and a critical component for optimal microbial growth, became more negative with garlic oil compared with the non-supplemented control treatment. The $\mathrm{pH}$ of the incubation liquid was not significantly different from that of the negative control with any test substance. None of the substances significantly differed from the negative control in the total concentration of SCFA, but levulinic acid increased SCFA concentration by $14 \%$, on average, relative to allyl isothiocyanate, chenodeoxycholic acid, lovastatin and PABA. The molar proportions of the individual SCFA were substantially altered by the test substances. Compared with the negative control, acetate proportion was higher with PABA $(+28 \%)$, lovastatin $(+7 \%)$ and levulinic acid $(+5 \%)$, similar to APEE and chenodeoxycholic acid, and lower with garlic oil and allyl isothiocyanate (both $-10 \%$ ). Regarding propionate proportion, PABA and lovastatin resulted in decreases of 48 and $24 \%$, respectively, relative to the negative control. Supplementation with allyl isothiocyanate resulted in the highest proportion of $n$-butyrate (significantly different from negative and positive controls, levulinic acid, lovastatin and PABA treatments). PABA treatment caused the lowest $n$-valerate proportion, while garlic oil, allyl isothiocyanate, chenodeoxycholic acid and levulinic acid resulted in a high proportion. Protozoal cell count was highest with APEE, which especially promoted the entodiniomorphs. Supplementation with chenodeoxycholic acid resulted in a complete defaunation of the incubation liquid. Supplementation with garlic oil increased bacterial cell counts by $30 \%$ compared with the negative control.

Supplementation with garlic oil, allyl isothiocyanate, lovastatin and APEE resulted in a decrease in daily absolute $\mathrm{CH}_{4}$ formation of $91,59,42$ and $98 \%$, respectively, compared with the negative control. The corresponding decreases in $\mathrm{CH}_{4}$ emitted were 91, 40, 42 and 98\%, respectively, expressed per unit of OM degraded, and 91, 40, 39 and 98\%, respectively (data not shown), expressed per unit of NDF degraded. When related to SCFA production, treatment differences were similar (Fig. 2). In contrast, supplementation with chenodeoxycholic acid and levulinic acid did not significantly alter $\mathrm{CH}_{4}$ formation. Garlic oil, allyl isothiocyanate and APEE supplementation increased total $\mathrm{H}_{2}$ production compared with the negative control. PABA supplementation was the only treatment that increased total daily $\mathrm{CH}_{4}$ formation.

The apparent in vitro OM disappearance was decreased with chenodeoxycholic acid supplementation when compared with the negative control, while the other test supplements had no significant effect (Table 2). Compared with the negative control, PABA decreased apparent CP (-11\%) and NDF $(-18 \%)$ disappearance, while chenodeoxycholic acid only decreased NDF disappearance $(-26 \%$ compared with the negative control). Apparently degraded and non-degraded $\mathrm{N}$ were $11 \%$ lower and $27 \%$ higher, respectively, following PABA supplementation, compared with the negative control. $\mathrm{NH}_{3}-\mathrm{N}$ was decreased, and non- $\mathrm{NH}_{3}-\mathrm{N}$ was increased following supplementation with chenodeoxycholic acid, lovastatin, levulinic acid, APEE and PABA compared with the non-supplemented basal diet. The estimated microbial efficiency was only affected by APEE, whose addition resulted in an increase of $24 \%$ compared with the negative control. The variables for $\mathrm{N}$ turnover were not affected by garlic oil and allyl isothiocyanate supplementation when compared with those of the negative control.

\section{Discussion}

The increasing body of literature dealing with nutritional means for abating enteric $\mathrm{CH}_{4}$ from ruminants and ruminal fermentation has now been compiled into several comprehensive reviews ${ }^{(25-27)}$. Despite extensive research to identify potential nutritional strategies that can decrease enteric $\mathrm{CH}_{4}$ formation, the set of options available for truly efficient mitigation at reasonable cost is still rather limited. However, numerous promising substances remain unexplored with respect to their efficacy.

\section{Garlic oil}

At a dosage of $300 \mathrm{mg} / \mathrm{l}$ of the incubation liquid, garlic oil caused an almost complete inhibition of $\mathrm{CH}_{4}$ production. It is important to note that this happened without any significant decrease in apparent $\mathrm{OM}$ and in NDF degradation. Other in vitro studies have also described $\mathrm{CH}_{4}$-mitigating properties of garlic oil ${ }^{(6)}$. In less than $24 \mathrm{~h}$ of incubation, $300 \mathrm{mg}$ garlic oil/1 decreased the absolute $\mathrm{CH}_{4}$ and $\mathrm{CH}_{4}$ related to SCFA by about $74 \%{ }^{(5)}$, while the corresponding decreases were 25 and $62 \%$, respectively, with 180 and $540 \mathrm{mg}$ garlic oil/ $\mathrm{l}^{(28)}$. The present results support the assumption made by Busquet et al. ${ }^{(5)}$ that ruminal Archaea are directly and selectively inhibited by garlic oil. However, the ruminal protozoa, often associated with the methanogens ${ }^{(29)}$, were also inhibited in the present study, indicating the occurrence of an additional indirect $\mathrm{CH}_{4}$-suppressing effect. Nevertheless, the $\mathrm{CH}_{4}$-suppressing effects resulting from defaunation are not always systematic $^{(11)}$. Several studies, including the present study, have shown that the anti-protozoal effect of garlic oil supplementation has frequently been associated with a corresponding change towards a lower acetate proportion ${ }^{(5,30,31)}$, although an experiment by Chaves et al. ${ }^{(6)}$ did not show this effect. Ohene-Adjei et $a l .^{(32)}$ observed a trend towards increased archaeal diversity after supplementation with essential oils other than garlic oil, which supports the existence of adaptive responses of the rumen microbial community to essential oils, as proposed by Busquet et al. ${ }^{(33)}$. At this point in time, the garlic oil compound or compounds responsible for the $\mathrm{CH}_{4-}$ suppressing effect have not yet been conclusively identified, and there may even be a synergistic effect of several of these compounds ${ }^{(5)}$. 
Table 1. Effects of supplemented natural and synthetic compounds on incubation liquid traits, counts of ruminal microbes and fermentation gas production (averages of days $6-10$ ) (Mean values with their pooled standard errors, $n 4$ )

\begin{tabular}{|c|c|c|c|c|c|c|c|c|c|c|}
\hline \multirow{2}{*}{$\begin{array}{l}\text { Origin of compound } \\
\text { Supplement }\end{array}$} & \multirow[b]{2}{*}{ None } & \multirow[b]{2}{*}{ Garlic oil } & \multicolumn{3}{|c|}{ Natural } & \multicolumn{3}{|c|}{ Synthetic } & \multirow[b]{2}{*}{ SEM } & \multirow[b]{2}{*}{$P$} \\
\hline & & & Allyl isothiocyanate & Lovastatin* & Chenodeoxycholic acid* & APEE & Levulinic acid & $\mathrm{PABA}^{*}$ & & \\
\hline \multicolumn{11}{|l|}{ Incubation liquid traits } \\
\hline Redox potential (mV) & $-192^{a}$ & $-249^{b}$ & $-215^{a}$ & $-206^{\mathrm{a}}$ & $-193^{\mathrm{a}}$ & $-194^{\mathrm{a}}$ & $-199^{a}$ & $-199^{a}$ & $5 \cdot 8$ & $<0.001$ \\
\hline $\mathrm{pH}$ & $6 \cdot 52^{a, b}$ & $6 \cdot 49^{\mathrm{a}, \mathrm{b}}$ & $6.53^{\mathrm{a}}$ & $6.51^{\mathrm{a}, \mathrm{b}}$ & $6.52^{\mathrm{a}}$ & $6 \cdot 40^{\mathrm{b}}$ & $6 \cdot 45^{\mathrm{a}, \mathrm{b}}$ & $6 \cdot 44^{\mathrm{a}, \mathrm{b}}$ & 0.025 & 0.012 \\
\hline $\mathrm{NH}_{3}(\mathrm{mmol} / \mathrm{l})$ & $11.5^{\mathrm{a}}$ & $12 \cdot 2^{\mathrm{a}}$ & $11.9^{\mathrm{a}}$ & $9 \cdot 4^{\mathrm{b}}$ & $9 \cdot 3^{\mathrm{b}}$ & $8 \cdot 8^{\mathrm{b}}$ & $9 \cdot 2^{\mathrm{b}}$ & $7.9^{\mathrm{b}}$ & 0.34 & $<0.001$ \\
\hline Total SCFA (mmol/l) & $116^{\mathrm{a}, \mathrm{b}}$ & $118^{a, b}$ & $110^{\mathrm{b}}$ & $107^{b}$ & $109^{b}$ & $117^{\mathrm{a}, \mathrm{b}}$ & $124^{a}$ & $108^{\mathrm{b}}$ & 2.9 & 0.004 \\
\hline \multicolumn{11}{|c|}{ Molar proportions ( $\%$ of SCFA) } \\
\hline Acetate & $52 \cdot 0^{\mathrm{d}}$ & $46.7^{\mathrm{e}}$ & $46 \cdot 7^{\mathrm{e}}$ & $55 \cdot 8^{\mathrm{b}}$ & $51 \cdot 3^{\mathrm{d}}$ & $52 \cdot 3^{\mathrm{c}, \mathrm{d}}$ & $54 \cdot 6^{\mathrm{b}, \mathrm{c}}$ & $66 \cdot 7^{\mathrm{a}}$ & 0.53 & $<0.001$ \\
\hline Propionate & $19 \cdot 9^{\mathrm{a}, \mathrm{b}}$ & $21.9^{\mathrm{a}}$ & $17 \cdot 4^{\mathrm{a}, \mathrm{b}, \mathrm{c}}$ & $15 \cdot 1^{\mathrm{c}, \mathrm{d}}$ & $17 \cdot 5^{\mathrm{a}, \mathrm{b}, \mathrm{c}}$ & $16 \cdot 8^{\mathrm{b}, \mathrm{c}}$ & $15 \cdot 9^{b, c}$ & $10 \cdot 4^{\mathrm{d}}$ & 1.00 & $<0.001$ \\
\hline$n$-Butyrate & $21 \cdot 3^{b, c}$ & $22 \cdot 3^{b, c}$ & $27 \cdot 1^{\mathrm{a}}$ & $22 \cdot 4^{b, c}$ & $23 \cdot 1^{a, b}$ & $25 \cdot 0^{a, b}$ & $21 \cdot 2^{b, c}$ & $18 \cdot 5^{\mathrm{c}}$ & 0.92 & $<0.001$ \\
\hline$n$-Valerate & $5 \cdot 82^{\mathrm{b}}$ & $7 \cdot 77^{\mathrm{a}}$ & $7 \cdot 64^{\mathrm{a}}$ & $5 \cdot 80^{\mathrm{b}}$ & $7 \cdot 37^{\mathrm{a}}$ & $4.97^{b}$ & $7 \cdot 34^{\mathrm{a}}$ & $3.41^{c}$ & 0.2445 & $<0.001$ \\
\hline \multicolumn{11}{|l|}{ Ruminal microbes } \\
\hline Entodiniomorphs $\left(\times 10^{3} / \mathrm{ml}\right)$ & $2 \cdot 37^{\mathrm{b}}$ & $0.35^{\mathrm{b}}$ & $2 \cdot 54^{\mathrm{b}}$ & $1 \cdot 24^{\mathrm{b}}$ & $0.00^{\mathrm{b}}$ & $7 \cdot 75^{\mathrm{a}}$ & $2 \cdot 72^{\mathrm{b}}$ & $0.06^{\mathrm{b}}$ & 0.603 & $<0.001$ \\
\hline Holotrichs $\left(\times 10^{3} / \mathrm{ml}\right)$ & $1 \cdot 18^{\mathrm{a}, \mathrm{b}}$ & $0.00^{\mathrm{b}}$ & $1 \cdot 18^{\mathrm{a}, \mathrm{b}}$ & $0.59^{\mathrm{a}, \mathrm{b}}$ & $0.00^{\mathrm{b}}$ & $1.77^{\mathrm{a}}$ & $1 \cdot 24^{a, b}$ & $0.59^{\mathrm{a}, \mathrm{b}}$ & 0.275 & 0.001 \\
\hline Bacteria $\left(\times 10^{8} / \mathrm{ml}\right)$ & $5.59^{b}$ & $7 \cdot 24^{\mathrm{a}}$ & $5 \cdot 63^{\mathrm{b}}$ & $6 \cdot 16^{a, b}$ & $6 \cdot 87^{\mathrm{a}, \mathrm{b}}$ & $6 \cdot 33^{a, b}$ & $6 \cdot 24^{a, b}$ & $6 \cdot 43^{\mathrm{a}, \mathrm{b}}$ & 0.274 & 0.005 \\
\hline \multicolumn{11}{|l|}{ Fermentation gas production } \\
\hline $\mathrm{H}_{2}(\mathrm{mmol} / \mathrm{d})$ & $0.20^{\mathrm{C}}$ & $2.09^{a}$ & $2 \cdot 16^{\mathrm{a}}$ & $0.91^{a, b, c}$ & $0.38^{\mathrm{b}, \mathrm{c}}$ & $1.51^{a, b}$ & $0.28^{\mathrm{c}}$ & $0.14^{c}$ & 0.245 & $<0.001$ \\
\hline $\mathrm{CH}_{4}(\mathrm{mmol} / \mathrm{d})$ & $7.96^{\mathrm{b}}$ & $0.73^{\mathrm{d}}$ & $4.77^{\mathrm{c}}$ & $4.59^{\mathrm{c}}$ & $7.44^{\mathrm{b}}$ & $0 \cdot 19^{d}$ & $7.86^{\mathrm{b}}$ & $11.49^{\mathrm{a}}$ & 0.310 & $<0.001$ \\
\hline
\end{tabular}

APEE, 3-azido-propionic acid ethyl ester; PABA, 4-[(pyridin-2-ylmethyl)-amino]-benzoic acid.

a,b,c,d Mean values within a row with unlike superscript letters were significantly different $(P<0 \cdot 05)$.

* The lovastatin, chenodeoxycholic acid and PABA treatments contained ethanol. 


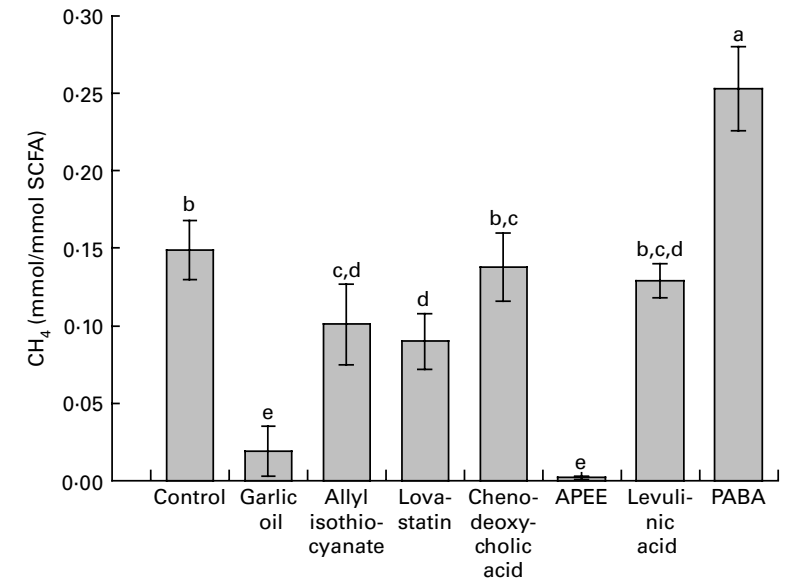

Fig. 2. Effects of supplemented natural and synthetic compounds on $\mathrm{CH}_{4}$ formation related to the total amount of SCFA synthesised. APEE, 3-azidopropionic acid ethyl ester; PABA, 4-[(pyridin-2-ylmethyl)-amino]-benzoic acid. Values are means (averages of days $6-10$ ), with standard errors represented by vertical bars $(n 4)$. ${ }^{a, b, c, d, e}$ Mean values with unlike letters were significantly different $(P<0.05)$.

\section{Allyl isothiocyanate}

The glucosinolate metabolite, allyl isothiocyanate $(75 \mathrm{mg} / \mathrm{l})$, was less efficient at $\mathrm{CH}_{4}$ mitigation than was garlic oil in the present study, but still substantially suppressed $\mathrm{CH}_{4}$ generation. This probably resulted from a direct effect on the methanogens, as indirect traits were not affected. In the study by Lila et al. ${ }^{(34)}$, addition of encapsulated allyl isothiocyanate at 75 and $145 \mathrm{mg} / \mathrm{l}$ of the incubation liquid (about $10 \%$ pure substance; the latter amount being approximately equal to what was used in the present study) suppressed $\mathrm{CH}_{4}$ production by 27 and $81 \%$, respectively. There was an increase in SCFA concentration and a decrease in $\mathrm{NH}_{3}$ concentration in the incubation liquid in response to the addition of encapsulated allyl isothiocyanate ${ }^{(34)}$, but no such changes were observed in the present study. In both studies, butyrate proportion increased following supplementation with allyl isothiocyanate.

\section{Lovastatin}

Lovastatin inhibits hydroxy-methylglutaryl-coenzyme A reductase $^{(8)}$, an enzyme used by eukaryotes and Archaea to synthesise mevalonate ${ }^{(35)}$. While eukaryotes employ mevalonate in the production of sterols, Archaea need it for the synthesis of the isoprenoid side chains of their unique and characteristic lipids $^{(35)}$. Lovastatin $(150 \mathrm{mg} / \mathrm{l})$ supplementation resulted in virtually the same level of $\mathrm{CH}_{4}$ suppression in the present study as was observed with allyl isothiocyanate. Again, this $\mathrm{CH}_{4}$-suppressing effect resulted from a direct mode of action, as neither protozoal counts nor nutrient fermentation were affected. In contrast to the $\mathrm{CH}_{4}$-mitigating results obtained in the present study, $5 \mathrm{mg} / \mathrm{l}$ of lovastatin tested by Busquet et al. ${ }^{(5)}$ did not affect ruminal methanogens during a $17 \mathrm{~h}$ incubation. A Methanobrevibacter strain, tested as a pure culture, was increasingly inhibited in its growth and its methanogenic activity with increasing dosages of

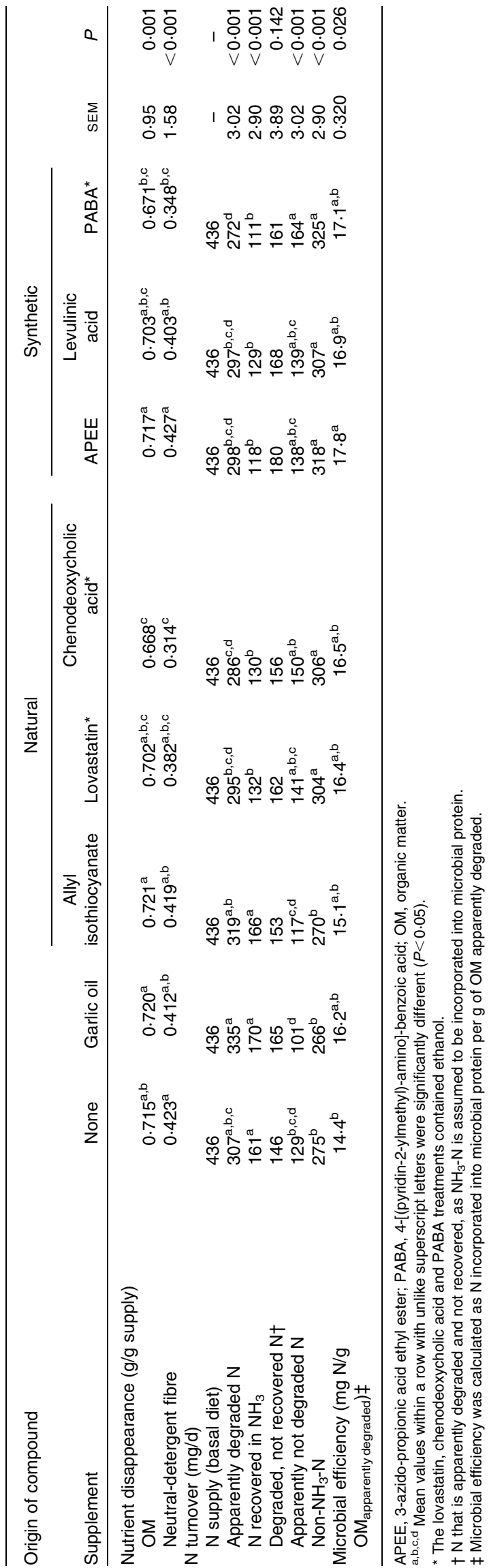


lovastatin, and a complete inhibition was possible ${ }^{(8)}$. In contrast, important ruminal bacterial species such as Butyrivibrio fibrisolvens, Ruminococcus albus, Ruminococcus flavefaciens, Fibrobacter succinogenes and Selenomonas ruminantium were unaffected by mevastatin, another inhibitor of the hydroxy-methylglutaryl-coenzyme A reductase ${ }^{(8)}$. In the present study, lovastatin did not affect SCFA concentration in the incubation liquid, as was also found in the short-term in vitro study by Busquet et al. ${ }^{(5)}$, who used a dosage about 30 -fold lower than that in the present study. It seems noteworthy that lovastatin reduced the amount of $\mathrm{N}$ recovered in $\mathrm{NH}_{3}$, suggesting the possibility of an N-saving effect for the ruminant. This effect was probably the result of the lower amount of $\mathrm{N}$ apparently degraded when compared with garlic oil. Busquet et $a l .{ }^{(5)}$, in contrast, did not find any lovastatin effects on $\mathrm{NH}_{3}-\mathrm{N}$ content.

\section{Chenodeoxycholic acid}

To the authors' knowledge, this is the first report of the addition of chenodeoxycholic acid to ruminant feed for the purpose of investigating its effects on ruminal methanogenesis and fermentation traits. This compound readily defaunated the incubation liquid and significantly depressed in vitro $\mathrm{OM}$ and NDF disappearance. Since protozoa are involved in ruminal nutrient degradation, including degradation of hemicellulose ${ }^{(36)}$, this would explain the decrease in NDF disappearance observed in the present study. Still, defaunation alone depresses fibre digestion only to a limited extent ${ }^{(37)}$, especially as bacteria fill this niche, as was partly the case $(+23 \%$ of counted bacteria) in the present study. Overall, the effects of chenodeoxycholic acid on the incubation liquid concentrations of SCFA were small. As with lovastatin, chenodeoxycholic acid decreased $\mathrm{N}$ recovered in $\mathrm{NH}_{3}$, which can be explained by its defaunating activity. Chenodeoxycholic acid was the only natural substance tested in the present study that did not have an effect on $\mathrm{CH}_{4}$ formation, despite its defaunating effect.

\section{3-Azido-propionic acid ethyl ester}

$\mathrm{CH}_{4}$ formation was drastically decreased to levels as low as those found with garlic oil following supplementation with the synthetic compound APEE. This decrease in $\mathrm{CH}_{4}$ formation seemed to have mainly resulted from an effect on the methanogens, as the amount of SCFA degraded was similarly reduced. At the same time, APEE very strongly supported the growth of the entodiniomorph protozoa. This effect was opposite to that found with added garlic oil and chenodeoxycholic acid, and suggests that the extra $\mathrm{H}_{2}$ supplied by these protozoa was not sufficient to compensate for its adverse action on the methanogens. A rather unexpected result was the decrease in ruminal $\mathrm{NH}_{3}$ formation, since protozoa, in addition to being $\mathrm{H}_{2}$ suppliers, are also major $\mathrm{NH}_{3}$ producers $^{(38)}$. The numerical decrease in apparent ruminal $\mathrm{N}$ disappearance might partly explain this observation; however, in general, APEE obviously promoted microbial efficiency (increase in estimated efficiency by $24 \%$ compared with the negative control).

\section{Levulinic acid}

Only few early reports are available concerning the application of levulinic acid, also called acetyl propionic acid, as a supplement to ruminant diets. Apparently, increasing levels $(2 \cdot 2-11 \cdot 3 \mathrm{mg} / \mathrm{g}$ feed) of levulinic acid improved cellulose digestion in a dose-dependent manner in dairy cattle ${ }^{(39)}$. This was not confirmed by Waldern et al. ${ }^{(14)}$, where levulinic acid $(11.3 \mathrm{mg} / \mathrm{g}$ feed) did not improve feed digestibility and even depressed microbial activity in dairy heifers and wethers. In the present study, $20 \mathrm{mg} / \mathrm{g}$ feed $(300 \mathrm{mg} / \mathrm{l})$ of levulinic acid decreased acetate and increased $n$-valerate proportion at an unchanged total amount of SCFA. Levulinic acid, although revealing no effect on nutrient fermentation and gaseous emissions, decreased incubation liquid $\mathrm{NH}_{3}$ concentration.

\section{4-[(Pyridin-2-ylmethyl)-amino]-benzoic acid}

The last synthetic compound tested, PABA, was shown to affect the incubation liquid SCFA profile. In an in vitro test ${ }^{(18)}$, PABA inhibited pure cultures of Methanothermobacter marburgensis, cultivated at $65^{\circ} \mathrm{C}$, but not of Methanobrevibacter smithii (a human hindgut species) cultivated at $37^{\circ} \mathrm{C}^{(40)}$. In the present study, ruminal methanogenesis was increased at an incubation temperature of $39^{\circ} \mathrm{C}$. In the study of Miner et $a l^{(18)}$, neither the growth of the acetogenic microbes nor that of the total ruminal cultures was inhibited by the addition of $10 \mathrm{~mm}$-PABA. The reduced nutrient disappearance observed with PABA also included that of dietary $\mathrm{N}$ compounds, resulting in a low $\mathrm{NH}_{3}-\mathrm{N}$ formation and, as a consequence, an increase in apparently not degraded $\mathrm{N}$. In the case where these apparently not degraded $\mathrm{N}$ compounds are digestible in the small intestine, this would be favourable, as it would improve metabolic protein supply and decrease metabolic $\mathrm{NH}_{3}$ load and $\mathrm{NH}_{3}$ emissions to the environment ${ }^{(41)}$.

\section{Conclusion}

In terms of medium-term $\mathrm{CH}_{4}$ mitigation by dietary supplements, garlic oil was largely superior to all other additions tested except for APEE. Two of the natural compounds, allyl isothiocyanate and lovastatin, were efficient $\mathrm{CH}_{4}$ mitigators as well, thus potentially worthy of further investigation under in vivo conditions. Besides carrying out toxicity tests with some of the pure substances, in vivo studies are required for confirming the anti-methanogenic properties shown in vitro. Further potential side effects of these compounds on feed intake, animal performance, the quality of the ruminant-source foods, as well as their economic viability, also have to be evaluated. Encapsulation, as practised, for instance, by Lila et al. ${ }^{(34)}$ with allyl isothiocyanate, might be a strategy to overcome potential palatability problems. Future research should also clarify the mode of action of $\mathrm{CH}_{4}$-mitigating compounds. Quantitative analysis on ruminal Archaea might be helpful in this respect. 


\section{Acknowledgements}

The present study was supported by DSM Nutritional Products AG, Kaiseraugst, Switzerland. The contribution of the authors was as follows: C. R. S. was responsible for the experimental design, statistical analysis and writing the manuscript; S. L. A. carried out the experiment and performed the analysis of the samples; S. M. D. advised on the experimental design and revised the manuscript; M. K., project leader, had a role in advising on the experimental design and revising the manuscript. The authors state that there is no conflict of interest.

\section{References}

1. Makkar HPS (2008) A review of the use of isotopic and nuclear techniques in animal production. Anim Feed Sci Technol 140, 418-443.

2. Beauchemin KA, Kreuzer M, O'Mara F, et al. (2008) Nutritional management for enteric methane abatement: a review. Aust J Exp Agric 48, 21-27.

3. Hart KJ, Yáňez-Ruiz DR, Duval SM, et al. (2008) Plant extracts to manipulate rumen fermentation. Anim Feed Sci Technol 147, 8-35.

4. Lawson L (1996) The composition and chemistry of garlic cloves and processed garlic. In The Science and Therapeutic Application of Allium sativum $L$. and Related Species, pp. 37-107 [HP Koch and LD Lawson, editors]. Baltimore, MD: Williams \& Williams.

5. Busquet M, Calsamiglia S, Ferret A, et al. (2005) Effect of garlic oil and four of its compounds on rumen microbial fermentation. J Dairy Sci 88, 4393-4404.

6. Chaves AV, He ML, Yang WZ, et al. (2008) Effects of essential oils on proteolytic, deaminative and methanogenic activities of missed ruminal bacteria. Can J Anim Sci 88, 117-122.

7. Duncan A \& Milne JA (1993) Effects of oral administration of brassica secondary metabolites, allyl cyanide, allyl isothiocyanate and dimethyl disulphide, on the voluntary food intake and metabolism of sheep. Br J Nutr 70, 631-645.

8. Miller TL \& Wolin MJ (2001) Inhibition of growth of methane-producing bacteria of the ruminant forestomach by hydroxymethylflutaryl-SCOA reductase inhibitors. J Dairy Sci 84, 1445-1448.

9. Prabha V \& Ohri M (2006) Review: bacterial transformations of bile acids. World J Microbiol Biotechnol 22, 191-196.

10. Binder HJ, Filburn B \& Floch M (1975) Bile acid inhibition of intestinal anaerobic organisms. Am J Clin Nutr 28, 119-125.

11. Martin C, Morgavi DP \& Doreau M (2010) Methane mitigation in ruminants: from microbe to the farm scale. Animal 4, 351-365.

12. Kitano M, Tanimoto F \& Okabayashi M (1975) Levulinic acid, a new chemical raw material; its chemistry and uses. Chem Econ Eng Rev 7, 25-29.

13. Ghorpade V \& Hanna MA (1997) Industrial applications for levulinic acid. In Cereal Novel Uses and Processes, pp. 49-55 [GM Campbell, C Webb and SL McKee, editors]. New York: Plenum Press.

14. Waldern DE, Roberts WK, Blosser TH, et al. (1961) Effect of levulinic acid on digestibility, fatty acid production and microbial activity in dairy heifers and wethers. J Anim Sci 20, 429-432.

15. Ghorpade V \& Hanna MA (1999) Method and apparatus for production of levulinic acid via reactive extrusion. US Patent Office, Patent no. 5,859,263.
16. Farone WA \& Cuzens J (2000) Method for the production of levulinic acid and its derivatives. US Patent Office, Patent no. 6,054,611.

17. Kajikawa H, Valdes C, Hillman K, et al. (2003) Methane oxidation and its coupled electron-sink reactions in ruminal fluid. Lett Appl Microb 36, 354-357.

18. Miner JL, Ragsdale SW \& Takacs JM (2003) Method for the inhibition of methanogenesis. US Patent Office, Patent no. 219467 A1.

19. Soliva CR \& Hess HD (2007) Measuring methane emission of ruminants by in vitro and in vivo techniques. In Measuring Methane Production from Ruminants, pp. 13-15 [HPS Makkar and PE Vercoe, editors]. Dordrecht: Springer.

20. Carro MD, Lebzien P \& Rohr K (1995) Effects of pore size of nylon bags and dilution rate on fermentation parameters in a semi-continuous artificial rumen. Small Rum Res 15, 113-119.

21. Soliva CR, Meile L, Cieślak A, et al. (2004) Rumen simulation technique study on the interaction of dietary lauric and myristic acid supplementation in suppressing ruminal methanogenesis. Br J Nutr 92, 689-700.

22. Ehrlich GG, Goerlitz DF, Bourell JH, et al. (1981) Liquidchromatographic procedure for fermentation product analysis in the identification of anaerobic bacteria. Appl Environm Microbiol 42, 878-885.

23. van Soest PJ, Robertson JB \& Lewis BA (1991) Methods for dietary fiber, neutral detergent fiber, and nonstarch polysaccharides in relation to animal nutrition. J Dairy Sci $\mathbf{7 4}$, 3583-3597.

24. SAS Institute, Inc. (2002) SAS version 9.2. Cary, NC: SAS Institute, Inc.

25. Johnson KA \& Johnson DE (1995) Methane emissions from cattle. J Anim Sci 73, 2483-2492.

26. Boadi D, Benchaar C, Chiquette J, et al. (2004) Mitigation strategies to reduce enteric methane emissions from dairy cows: update review. Can J Animal Sci 84, 319-335.

27. Monteny GJ \& Chadwick D (2006) Greenhouse gas abatement strategies for animal husbandry. Agric Ecosyst Environ 112, 163-170.

28. Kamel C, Greathead HMR, Ranilla MJ, et al. (2009) The effects of garlic oil on in vitro rumen fermentation and methane production are influenced by the basal diet. In Ruminant Physiology: Digestion, Metabolism, and Effects of Nutrition on Reproduction and Welfare, pp. 234-235 [Y Chilliard, F Glasser, Y Faulconnier, F Bocquier, I Veissier and M Doreau, editors]. Proceedings of the XIth International Symposium on Ruminant Physiology, Wageningen: Wageningen Acdemic Publisher.

29. Stumm CK \& Zwar KB (1986) Symbiosis of protozoa with hydrogen-utilizing methanogens. Microbiol Sci 3, 100-105.

30. Cardozo PW, Calsamiglia S, Ferret A, et al. (2005) Screening for the effects of natural plant extracts at different $\mathrm{pH}$ on in vitro rumen microbial fermentation of a high concentrate diet for beef cattle. J Anim Sci 83, 2572-2579.

31. Kamel C, Greathead HMR, Tejido ML, et al. (2008) Effects of allicin and diallyl disulfide on in vitro rumen fermentation of a mixed diet. Anim Feed Sci Technol 145, 351-363.

32. Ohene-Adjei S, Chaves AV, McAllister TA, et al. (2008) Evidence of increased diversity of methanogenic Archaea with plant extract supplementation. Microb Ecol 56, 234-242.

33. Busquet M, Calsamiglia S, Ferret A, et al. (2005) Effects of cinnamaldehyde and garlic oil on rumen microbial fermentation in a dual flow continuous culture. J Dairy Sci $\mathbf{8 8}, 2508-2516$. 
34. Lila ZA, Mohammed N, Kanda S, et al. (2003) Effect of $\alpha$-cyclodextrin-allyl isothiocyanate on ruminal microbial methane prodcution in vitro. Anim Sci J 74, 321-326.

35. Lam WL \& Ford Doolittle W (1992) Mevinolin-resistant mutations identify a promoter and the gene for a eukaryote-like 3-hydroxy-3-methylglutaryl-coenzyme A reductase in the archaebacterium Haloferax volcanii. J Biol Chem $\mathbf{2 5}$ 5829-5834.

36. Williams AG \& Coleman GS (1985) Hemicellulose-degrading enzymes in rumen ciliate protozoa. Curr Microbiol $\mathbf{1 2}$ 85-90.

37. Newbold CJ, Griffin PW \& Wallace RJ (1989) Interactions between rumen bacteria and ciliate protozoa in their attachment to barley straw. Lett Appl Microb 8, 63-66.
38. Males JR \& Purser DB (1990) Relationship between rumen ammonia levels and the microbial population and volatile fatty acid proportions in faunated and defaunated sheep. Appl Microbiol 19, 485-490.

39. Kamlet J (1958) Preservation and improvement of assimilability of feeding stuffs. US Patent Office, Patent no. $2,831,769$

40. Weaver GA, Krause JA, Miller TL, et al. (1986) Incidence of methanogenic bacteria in a sigmoidoscopy population: an association of methanogenic bacteria and diverticulosis. Gut 27, 698-704.

41. James T, Meyer D, Esparza E, et al. (1999) Effects of dietary nitrogen manipulation on ammonia volatilization from manure from Holstein heifers. J Dairy Sci 82, 2430-2439. 